\title{
Burnout Among Physicians in Qalubia Primary Health Care Facilities, Egypt
}

\author{
Taghreed Mohamed Farahat ${ }^{1}$, Nagwa Nashat Hegazy ${ }^{1}$, Dalia Hamed Mohamed ${ }^{2}$ \\ ${ }^{1}$ Family Medicine Department, Faculty of Medicine, Menofiya University, Menofia Governorate, Egypt \\ ${ }^{2}$ Residence of Family Medicine in Gezirat -El Shair Family Health Center, El Kanater Elkharia Distract, Qalubia Governorate, Egypt
}

Email address:

nagwanashat@hotmail.com (N. N. Hegazy)

\section{To cite this article:}

Taghreed Mohamed Farahat, Nagwa Nashat Hegazy, Dalia Hmed Mohamed. Burnout Among Physicians in Qalubia Primary Health Care Facilities, Egypt. Journal of Family Medicine and Health Care. Vol. 2, No. 1, 2016, pp. 1-5. doi: 10.11648/j.jfmhc.20160201.11

\begin{abstract}
Background: Burnout carries a potential negative effect on the individual's psychological and physical health, as well as an organization's effectiveness. Therefore, it is recognized worldwide as a major challenge to workers' health and the functioning of their organizations. Objectives: Determine the prevalence of burnout among physicians in the primary health care facilities and identify the physical predictors of burnout syndrome. Participants \& Methods: The study was a cross sectional study conducted on 76 physicians in El Kanater El Kharaia distract PHC units \& centers in Qalubia Governorate, Egypt. It was conducted in the context of 10 months. All the participants were interviewed using Maslach burnout inventory. Results: Nearly $66.7 \%$ of the general practioners (GPs) had high burnout while only $26.7 \%$ of specialists had high burnout. Emotional exhaustion was higher in GPs than family physician and specialist. It was $80.7 \%, 75 \%$ and $46.7 \%$ respectively (p value $<0.001)$. High depersonalization was in GPs resembling $89.5 \%$ compared to $50 \%$ and $40 \%$ in family physician and specialist respectively ( $\mathrm{p}$ value $<0.001$ ). Nearly two third of the specialists had high personal accomplishment in comparison to $40.3 \%$ and $22 \%$ in GPs \& family physicians. Multivariate regression analysis showed that the most relevant risk factor for burnout was low income and the most relevant physical predictors for burnout were being angry and being hurry ( $\mathrm{p}$ value $<$ 0.05). Conclusion: Primary care physicians suffer from burnout more than family physicians and specialists. High burnout was prevalent with those under 30 years old and less than 5 years of experience.
\end{abstract}

Keywords: Physicians, Burnout, PHC

\section{Introduction}

Burnout has been defined as a psychological syndrome that may emerge when employees are exposed to a stressful working environment with high job demands and low resources [1] [2] [3]. Burnout is a physical, mental, and emotional response to constant high levels of stress and ineffective or inadequate coping methods [4]. It is typically conceptualized as a syndrome characterized by emotional exhaustion, depersonalization, and reduced personal accomplishment [5].

Medical practice is stressful. This is because medical personnel must respond to the needs of patients and families very quickly. Any medical errors or mistakes may be costly, harmful to a patient's life and sometimes irreversible. Moreover, night work, shift work and long work hours are also very common in medical professions [6]. The identified factors for the etiology of burnout among healthcare workforce include inadequate staff, long working hours, financial constraints, inadequate supervision or leadership skills of departmental heads, witnessing death and dying in practice, frequent conflicts among healthcare professionals, stressors in private life and lack of social support [7] [8] [9]. The most commonly used tool for assessing burnout is the 22-item Maslach Burnout Inventory-Human Services Survey (MBI-HSS) [10]. The impacts of burnout not only affect the suffering physicians but extend to affect their patients. Loss of job satisfaction, high rates of turnover in addition to depressive disorders, poor job performance and high rates of absenteeism are among the numerous impacts of burnout on physicians [11].

\subsection{Objectives}

Determine the prevalence of burnout among physicians in the primary health care facilities and identify the physical predictors of burnout syndrome 


\subsection{Subjects and Methods}

The study was a cross sectional study. It was conducted in the context of time frame of 10 months (starting on the $1^{\text {st }}$ of August, 2014 till the end of April of 2015) with all the physicians working in the family health centers and unites in El kanater el khariaa district, Kaluobia governorate, Egypt. It embraces 5 family health centers and 16 family health units in El kanater el khariaa District.

Human rights and ethical considerations were followed during the study, with total confidentiality of any obtained data. The Menoufia Faculty of Medicine Committee for Medical Research Ethics reviewed and formally approved the study before it began. A written consent form was taken from the local health care authorities in the studied centers as well as from all participants after explaining the aim of the study.

A pilot study was done on 10 participants. They were interviewed using a semi-structured questionnaire with the following sections:

First part: Physician socio demographic data to obtain: Name, age, sex, occupation, marital status, number of children, income, years of experience and the weekly hours of work

Second part: contains an arabic valid reliable version of Maslach burnout inventory (MBI) [12]. A 22 items of MBI were asked to assess the three domains of burnout syndrome; emotional exhaustion (EE), depersonalization (DP) and personal accomplishment (PA) then the burnout score was calculated [10].
Third part: contains questions to assess the physical and emotional symptoms, as physical predictors. No modifications were done on the tools and the number was added to the study.

All the physicians working in the selected area were invited to participate in the study. The registered working number during the period of the study was 83 physicians. Only 13 physicians resembling $8.4 \%$ of the registered physicians refused to share in the research. The 76 participants were divided into three groups:

1) General practioners were 57 participants accounting $75 \%$

2) family physicians were 4 participants resembling $5 \%$

3) specialists were 15 participants resembling nearly $20 \%$

\section{Statistical Analysis}

The results were collected, tabulated, and analyzed statistically using Microsoft Excel and SPSS, version 17 software programs (SPSS Inc., Chicago, Illinois, USA). Data were described as frequencies (number of cases) and relative frequencies (percentages) when appropriate. It was analyzed applying Chi-square test to compare more than two qualitative groups, Odds ratio to determine significant risk factors and Step wise regression test to test association between variables and detection of risk factors. A probability value ( $P$-value) less than 0.05 was considered statistically significant.

\section{Results}

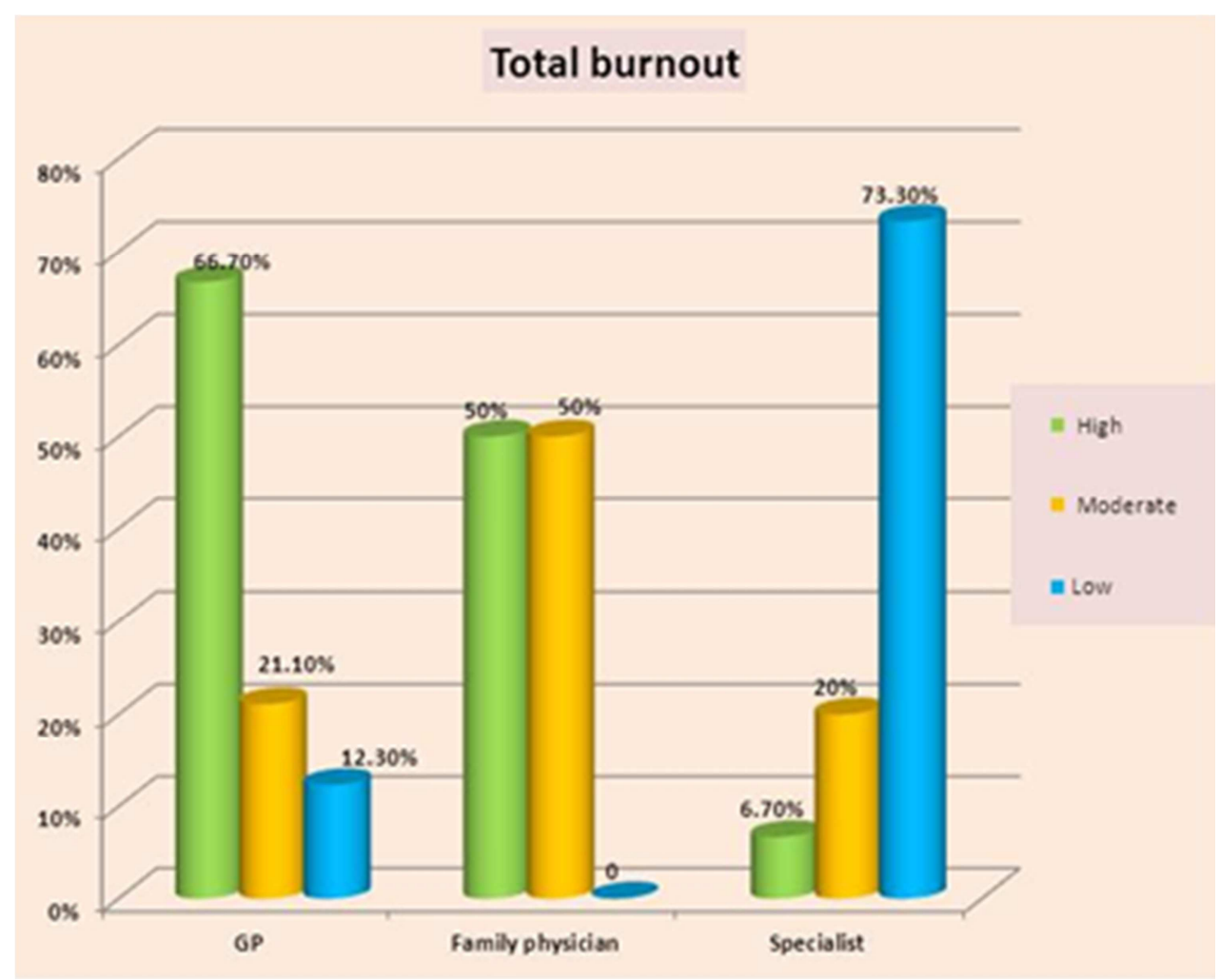

Fig. 1. Total burnout among the studied groups. 
Table 1. Levels of burnout among studied group $(N=76)$.

\begin{tabular}{|c|c|c|c|c|c|c|c|c|}
\hline \multirow{3}{*}{ Burnout subscale } & \multicolumn{6}{|c|}{ Studied group } & \multirow{3}{*}{$\chi^{2}$} & \multirow{3}{*}{ P value } \\
\hline & \multicolumn{2}{|c|}{ GP $(n=57)$} & \multicolumn{2}{|c|}{ Family physician $(n=4)$} & \multicolumn{2}{|c|}{ Specialist $(n=15)$} & & \\
\hline & No. & $\%$ & No. & $\%$ & No. & $\%$ & & \\
\hline \multicolumn{9}{|l|}{ Emotional exhaustion } \\
\hline High & 46 & 80.7 & 3 & 75.0 & 7 & 46.7 & \multirow{3}{*}{17.6} & \multirow{3}{*}{0.001} \\
\hline Moderate & 9 & 15.8 & 1 & 25.0 & 2 & 13.3 & & \\
\hline Low & 2 & 3.5 & 0 & 0.0 & 6 & 40.0 & & \\
\hline \multicolumn{9}{|l|}{ Depersonalization } \\
\hline High & 51 & 89.5 & 2 & 50.0 & 6 & 40.0 & \multirow{2}{*}{18.6} & \multirow{2}{*}{0.001} \\
\hline Moderate & 6 & 10.5 & 2 & 50.0 & 9 & 60.0 & & \\
\hline \multicolumn{9}{|l|}{ Accomplishment } \\
\hline High & 23 & 40.3 & 1 & 22.0 & 10 & 66.7 & \multirow{3}{*}{7.1} & \multirow{2}{*}{0.02} \\
\hline moderate & 30 & 52.6 & 3 & 75.0 & 5 & 33.3 & & \\
\hline \multicolumn{8}{|l|}{ Total burnout } & \\
\hline High & 38 & 66.7 & 2 & 50.0 & 1 & 6.7 & \multirow{3}{*}{29.1} & \multirow{3}{*}{0.001} \\
\hline Moderate & 12 & 21.1 & 2 & 50.0 & 3 & 20.0 & & \\
\hline Low & 7 & 12.3 & 0 & 0.0 & 11 & 73.3 & & \\
\hline
\end{tabular}

Table 2. Relationship between total burnout and socio demographic characters of studied group $(N=76)$ :

\begin{tabular}{|c|c|c|c|c|c|c|c|c|}
\hline \multirow{3}{*}{ Socio demographic } & \multicolumn{6}{|c|}{ Burnout } & \multirow{3}{*}{$\chi^{2}$} & \multirow{3}{*}{ P value } \\
\hline & \multicolumn{2}{|c|}{ High $(n=41)$} & \multicolumn{2}{|c|}{ Moderate(n=17) } & \multicolumn{2}{|c|}{ Low $(n=18)$} & & \\
\hline & No. & $\%$ & No. & $\%$ & No. & $\%$ & & \\
\hline \multicolumn{9}{|l|}{ Age/years: } \\
\hline$-\leq 30$ & 29 & 70.7 & 8 & 47.1 & 4 & 22.2 & 12.3 & 0.002 \\
\hline$->30$ & 12 & 29.3 & 9 & 52.9 & 14 & 77.8 & & \\
\hline \multicolumn{9}{|l|}{ Gender: } \\
\hline Female & 21 & 51.2 & 11 & 64.7 & 8 & 44.4 & 1.5 & 0.47 \\
\hline Male & 20 & 48.8 & 6 & 35.3 & 10 & 55.6 & & \\
\hline \multicolumn{9}{|l|}{ Number of children: } \\
\hline$<3$ & 37 & 90.2 & 13 & 76.5 & 13 & 72.2 & 3.51 & 0.17 \\
\hline$\geq 3$ & 4 & 9.8 & 4 & 23.5 & 5 & 27.8 & & \\
\hline \multicolumn{9}{|l|}{ Marital state: } \\
\hline Single & 20 & 48.8 & 12 & 70.6 & 16 & 88.9 & 9.16 & 0.01 \\
\hline Married & 21 & 51.2 & 5 & 29.4 & 2 & 11.1 & & \\
\hline \multicolumn{9}{|l|}{ Occupation: } \\
\hline GP & 38 & 92.7 & 12 & 70.6 & 7 & 38.9 & \multirow{3}{*}{29.1} & \multirow{3}{*}{0.001} \\
\hline Family physician & 2 & 4.9 & 2 & 11.8 & 0 & 0 & & \\
\hline Specialist & 1 & 2.4 & 3 & 17.6 & 11 & 61.1 & & \\
\hline \multicolumn{9}{|l|}{ Income: } \\
\hline$<2000$ & 33 & 80.5 & 11 & 64.7 & 5 & 27.8 & \multirow[t]{2}{*}{15.1} & \multirow[t]{2}{*}{0.001} \\
\hline$>2000$ & 8 & 19.5 & 6 & 35.3 & 13 & 72.2 & & \\
\hline \multicolumn{9}{|l|}{ Years of experience: } \\
\hline$<5$ & 31 & 75.6 & 9 & 52.9 & 5 & 27.8 & \multirow[t]{2}{*}{12.2} & \multirow[t]{2}{*}{0.002} \\
\hline$\geq 5$ & 10 & 24.4 & 8 & 47.1 & 13 & 72.2 & & \\
\hline
\end{tabular}

Table 3. Binary logistic regression analysis of socio demographic risk factors of burnout.

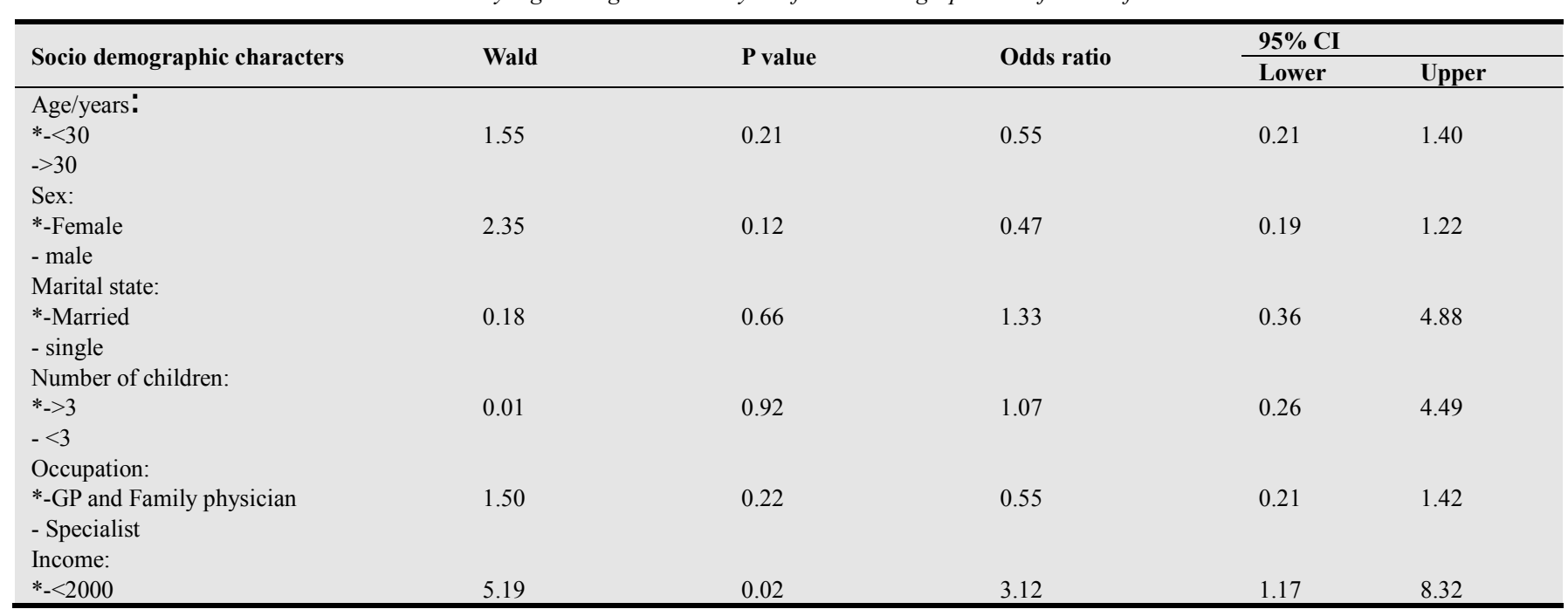




\begin{tabular}{lllll}
\hline Socio demographic characters & Wald & P value & Odds ratio & 95\% CI \\
\hline $\begin{array}{l}->2000 \\
\begin{array}{l}\text { Years of experience: } \\
*-<5 \text { years } \\
-\geq 5 \text { years }\end{array}\end{array}$ & & & Lower & Upper \\
\hline
\end{tabular}

Table 4. Binary logistic regression analysis of physical predictors of burnout.

\begin{tabular}{llllll}
\hline \multirow{2}{*}{ physical predictors } & Wald & P value & \multirow{2}{*}{ Odds ratio } & & 95\% CI \\
\cline { 4 - 6 } & & & Lower & Upper \\
\hline Headache & 1.43 & 0.232 & 2.72 & 0.52 & 14.1 \\
Being angry & 9.52 & 0.002 & 0.09 & 0.02 & 0.42 \\
Appetite changes & 1.50 & 0.220 & 0.21 & 0.01 & 2.47 \\
Increased blood pressure & 0.001 & 0.996 & 1.004 & 0.21 & 4.64 \\
Pain in back and neck & 0.003 & 0.956 & 1.04 & 0.25 & 4.19 \\
Increased smoking & 0.358 & 0.550 & 0.61 & 0.12 & 3.02 \\
Infections & 0.001 & 0.977 & 1.02 & 0.26 & 3.90 \\
Lack of concentration & 1.11 & 0.291 & 0.31 & 0.03 & 2.69 \\
Dyspepsia & 1.48 & 0.223 & 0.33 & 0.05 & 1.94 \\
Being hurry & 8.72 & 0.003 & 0.09 & 0.02 & 0.45 \\
\hline
\end{tabular}

Fig (1): Shows the burnout among the studied group. There was a significant difference among the studied groups where high burnout was noted in $66.7 \%$ of general practitioners and $50 \%$ in the family physicians while only $6.7 \%$ of the specialist had high burnout.

Table (1): This table showed that there was a statistically significant difference in burnout subscales. Emotional exhaustion and depersonalization were higher in general practitioner than family physician and specialist. Nearly two third resembling $66.7 \%$ of general practitioner had high total burnout.

Table (2): This table showed that the socio-demographic data of the studied groups working in the primary health care units and centers in EL-kanater distract. Nearly half of the studied group were females. The mean age of the participants was 33.7 years. There was a highly significant difference in age, marital state, occupation, income, years of experience and total burnout score. High burnout was in age less than 30, married, general practitioner, doctors with income less than 2000 LE and years of experience less than 5years old.

Table (3) this table shows the binary logistic regression analysis of socio demographic risk factors of burnout.

Table (4): This table showed the multivariate regression analysis of the most relevant physical predictors for burnout among doctors. physical predictors for burnout among doctors reveals that the most significant physical predictors is angry and hurry, while some physicians suffer from headache, appetite changes and lack of concentration, but with less significant value.

\section{Discussion}

Nearly two third of the general practioners had high burnout which is in agreement with Youssef et al., 2006 who found that $63.1 \%$ of the residents meeting the burnout criteria [13]. This is in agreement with a cross-sectional survey of family physicians that was conducted in 12 European countries using maslash burnout inventory human services survey (MBI-HSS) where out of the responding 1393 physician, 43\% scored high for emotional exhaustion (EE) burnout, $35 \%$ for depersonalization (DP) and 32\% for personal accomplishment [14]. This figure is similar to other figures in the area e.g.: $63.2 \%$ in Yemen [15]. The complex nature of providing accessible, continuing, and comprehensive care to patients and their families and managing ethical dilemmas, puts family physicians at high risk of depletion of their emotional resources and developing burnout. This is opposing studies on primary care doctors or general practitioners in several western European countries, including Switzerland, Italy and France which reported prevalence rate ranging from around $20 \%$ to more than $50 \%$ in some studies [16].

A significant relation between age and high $\mathrm{EE}$ was identified, the data about the relationship between age and burnout reported in other studies, are conflicting. Some studies among physicians in USA and Canada found out that younger physicians are more susceptible to burnout and some found a negative correlation between age and burnout [17]. hypothesized that the reason for higher level of burnout among younger people is working experiences, so the risk of burnout is greater at the beginning of career.

Some studies showed that there is a higher level of burnout among female physicians, which could be due to the responsibility of women for the house hold and their families, especially if they have children, [17]. A higher percentage of female physicians reported burnout which may be attributed to the fact that women tend to enter generalist professions (family medicine and internal medicine) rather than the lower-stress subspecialties. Women may also have more conflicts between work and home, particularly if they have children [18].

The current study had showed that there was a highly significant difference in age, marital state, occupation, income, years of experience and total burnout score. High burnout was distinguished in participants less than 30 years old, married, works as general practitioner, with an income 
less than $2000 \mathrm{~L}$. E and their years of experience was less than 5 years $(P$ value $<0.001)$. This is in a concordance with a new survey conducted by Medscape. It showed that nearly half of family physicians younger than 35 years feel burned out. This is a substantial increase over the rates documented in the 2013 Medscape survey [19].

This also in agreement with a study conducted in Saudi Arabia by Selaihem, 2013. It showed that High burnout was found to be strongly associated with several of the variables under study, especially low job satisfaction, expressed intention to change job, tobacco consumption and use of psychotropic medication, younger age, recent graduation and married ones [20].

With multivariate regression analysis of the most relevant risk factor for burnout among doctors revealed that the most significant risk factor was low income, $\mathrm{p}$ value $<0.05$.

\section{Conclusion and Recommendations}

It seems that primary care physicians suffer from burnout more than family physicians and specialists. The presence of burnout is a serious phenomenon, because it can lead to psychosomatic complaints, work-associated withdrawal behavior, and a lower quality of care at the primary health care units and centers. training plans about coping strategies with burnout.

\section{References}

[1] Freudenberger HJ (1974): Staff burnout. J Soc Issues; 30: 159-65.

[2] Maslach C, Schaufeli WB, Leiter MP (2001): Job burnout. Annu Rev Nurses: Psychol; 52: 397-422.

[3] Bakker AB, Demerouti E (2007): The job demands-resources model: state of the art. J Manager Psychol; 22: 309-28.

[4] White, R A (2006): Perceived Stressors, Coping Strategies, and Burnout Pertaining to Psychiatric Nurses Working on Locked Psychiatric Units. MASTER Thesis OF SCIENCE in Nursing, College of Health and Human Services, Eastern Michigan University, October 21, 2006.

[5] Jennings B M (2006): Work Stress and Burnout Among Nurses: Role of the Work Environment and Working Conditions Agency for Healthcare Research and Quality, Chapter 26, 2008.

[6] Chou L-P, Li C-Y Hu SC (2014): Job stress and burnout in hospital employees: comparisons of different medical professions in a regional hospital in Taiwan. BMJ Open; 4: e004185.
[7] Iglesias, M. E, Vallejo, R. B \& Fuentes, P. S (2010): Reflections on the burnout syndrome and its impact on health care providers. Annals of African Medicine, 9: 197-8.

[8] Arigoni. F., Bovier. P., A., \& Sappino. A. (2010): Trend in burnout among Swiss doctors. Swiss Medical Weekly, 140: $10-17$.

[9] Lasebikan. V., O., \& Oyetunde. M., O. (2012): Burnout among nurses in a Nigerian General hospital: prevalence and associated factors. International Scholarly Research Network, Article ID 402157: 1-6.

[10] Maslach C, Jackson S, Leiter M. (1996): Maslach burnout inventory manual. Palo Alto: Consulting Psychologists.

[11] Vahey D., Aiken L H., Sloane D M., Clarke S P, and Vargas D. (2004): Nurse Burnout and patient satisfaction. Medical care; 42, 2 II-57. Copyright (C) 2004 by Lippincott Williams \& Wilkins.

[12] 21. mohammed Hamza. (2007): source of burnout in teachers in special education in El Kark governate and its relation in some changes. collage of science Mataa university. Journal of the university, second edition No 23 page 218. http//:www.gulfkids.com/pdf/Burn-Jordaan2.pdf.ss

[13] Yousef I, Hosny A, Elsayed O, Ali E. (2006); Burnout Syndrome among Resident Physician in Suez Canal University Hospital. Current Psychiatry. 14(1): 24-43.

[14] Leiter MP, Frank E, Matheson TJ. Demands, values and burnout; relevance for physicians, can FAM physicians 2009 Dec; 55(12): 1224-1225.

[15] Al-Dubai AR, Rampal KG. (2010). Prevalence and associated factors of burnout among doctors in Yemen. J Occup Health; 52: 58_65.

[16] Klemenc-Ketiš Z, Kersnik J ojstersek J. (2008). perceived difficulties in managing ethical problems in family practice in solvenia; Croat Med J; 49: (6) 799-806.

[17] Lee FJ, Brown JB, Stewart M. Exploring family physician stress: helpful strategies. Can FAM Physician 2009.

[18] Chopra S, Sotile W, Sotile M (2004): Physician burnout. JAMA; 291: 633.

[19] Medscape survey: family physician life styles - linking to burnout, 2013. http://www.medscape.com/features/slideshow/lifestyle/2013/p ublic last accessed September 2015.

[20] Selaihem A (2013). Prevalence of burnout amongst physicians working in primary care in Riyadh military hospital, Saudi Arabia. Int J Med Sci Public Health; 2: 410-419. 